
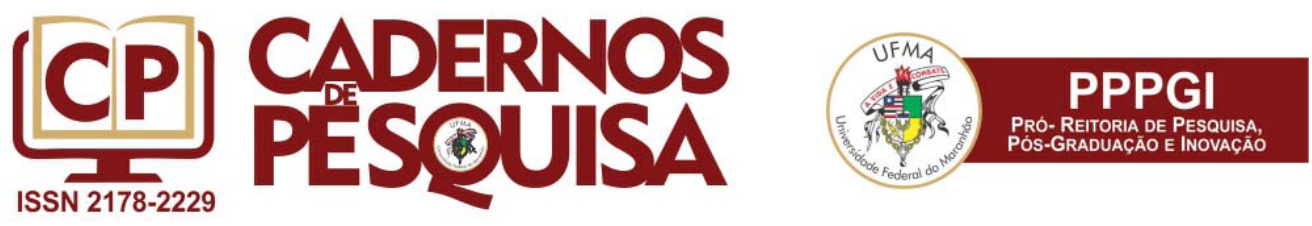

\title{
CARACTERIZAÇÃO DAS ATITUDES DE DISCENTES DO ENSINO MÉDIO DO MUNICÍPIO DE PARINTINS EM RELAÇÃO À EDUCAÇÃO FÍSICA ESCOLAR
}

\author{
CHARACTERIZATION OF THE ATTITUDES OF HIGH SCHOOL STUDENTS FROM \\ THE CITY OF PARINTINS IN RELATION TO SCHOOL PHYSICAL EDUCATION
}

\author{
CARACTERIZACIÓN DE LAS ACTITUDES DE DISCENTES \\ DE LA ENSEÑANZA MEDIA DEL MUNICIPIO DE PARINTINS \\ EN RELACIÓN A LA EDUCACIÓN FÍSICA ESCOLAR
}

\author{
Henrique Júnior Batista Pereira \\ Pós-Graduado em Educação Física e Nutrição Escolar pela Faculdade Kurios \\ Maranguape-CE, Brasil. \\ henrique_prof.edu.fisica@outlook.com \\ Dirceu Ribeiro Nogueira da Gama \\ Professor Doutor do Departamento de Ciências da Atividade Física (DECAF) do Instituto de \\ Educação Física e Desportos da Universidade do Estado do Rio de Janeiro (UERJ). \\ Rio de Janeiro-RJ, Brasil. \\ dirceugama@ufam.edu.br
}

\begin{abstract}
Resumo
O objetivo do presente estudo, cujo perfil é de natureza exploratória e descritiva, consiste em caracterizar as atitudes de discentes do ensino médio do município de Parintins, Amazonas, face ao cotidiano das suas aulas de Educação Física escolar. Para isso, parte-se da concepção teórica de que atitudes são disposições para comportamentos construídas em franca interação com o meio ambiente externo. Para a coleta de informações empíricas, empregaram-se dois instrumentos: um questionário sociodemográfico, para levantar informações sobre sexo, idade e instituição de ensino do respondente; e a "Escala Adams", para medição de atitudes discentes em relação ao professor de Educação Física. Os dados obtidos foram tabulados segundo os procedimentos de estatística descritiva simples (média aritmética e desvio padrão) e por variável controlada (sexo, grupos de idades e escola). Para a análise por sexo, recorreu-se ao teste "t" e, para as análises por idades e escola, empregou-se a Análise de Variância (ANOVA) com entrada simples $(p<0.05)$. Os resultados mostram a inexistência de diferenças estatisticamente significativas tanto para a variável sexo quanto para escola e grupos de idades em relação às atitudes de discentes nas aulas de Educação Física.
\end{abstract}

Palavras-chave: Atitudes. Discentes. Ensino Médio. Educação Física Escolar.

\begin{abstract}
The aim of the present study, whose profile is exploratory and descriptive, is to characterize the attitudes of high school students from the city of Parintins, Amazon, considering their daily school physical education classes. For this it starts from the theoretical concept that attitudes are disposition for behaviors built in interaction with the external environment. To collect empirical data, two instruments were employed: a sociodemographic questionnaire, to gather information on sex, age and educational institution of the respondent, and the "Adams Scale" to measure students' attitudes regarding the physical education teacher. The data were tabulated according to the procedures of simple descriptive statistics (arithmetic mean and standard deviation) and also controlled variable (sex, age groups and school). For the analysis by gender, the " $\mathrm{t}$ " test was used, and for age and school, we used the analysis of variance (ANOVA) with single input $(p<0.05)$ one. The results show the absence of statistically significant differences for both sex and school and age groups in relation to students' attitudes in physical education classes.
\end{abstract}

Keywords: Attitudes. Students. Middle School. School Physical Education.

Artigo recebido em maio 2017. Aprovado em setembro de 2017.

Cad. Pesq., São Luís, v. 25, n. 2, abr./jun. 2018. 


\section{Resumen}

El objetivo del presente estudio, cuyo perfil es de naturaleza exploratoria y descriptiva, consiste en caracterizar las actitudes de los discentes de la enseñanza media del municipio de Parintins, Amazonas, frente al cotidiano de sus clases de educación física escolar. Para ello, se parte de la concepción teórica de que actitudes son disposiciones para comportamientos construidos en franca interacción con el medio ambiente externo. Para la recolección de informaciones empíricas, se emplearon dos instrumentos: un cuestionario socio demográfico, para levantar informaciones sobre sexo, edad e institución de enseñanza del encuestado, y la "Escala Adams" para medición de actitudes discentes en relación al profesor de educación física. Los datos obtenidos fueron tabulados según los procedimientos de estadística descriptiva simple (media aritmética y desviación estándar) y también por variable controlada (sexo, grupos de edades y escuela). Para el análisis por sexo, se recurrió a la prueba "t", mientras que, para los análisis por edades y escuela, se empleó el análisis de varianza (ANOVA) con entrada simple $(p<0.05)$. Los resultados muestran la inexistencia de diferencias estadísticamente significativas tanto para el sexo como por la escuela y grupos de edad en relación a las actitudes de los estudiantes en las clases de educación física.

Palabras clave: Actitudes. Discentes. Enseñanza Media. Educación Física Escolar.

\section{INTRODUÇÃO}

Nos últimos trinta anos, uma característica marcante do campo acadêmico da Educação Física brasileira vem sendo a elaboração de diversas (e muitas vezes divergentes) orientações teórico-metodológicas, estabelecendo objetivos, procedimentos de ação e critérios avaliativos a serem cumpridos por essa disciplina no âmbito da esfera escolar.

Com base nos levantamentos feitos por Tubino (2002) e Darido (2003), pode-se dizer que tais concepções, também chamadas de abordagens, são as seguintes até o presente momento: desenvolvimentista; construtivista; crítico-superadora; sistêmica; tecnicista; psicomotora; crítico-emancipatória; culturalista; humanista; da saúde via aptidão física; da saúde renovada; dos jogos cooperativos; dos parâmetros curriculares nacionais; e do olimpismo.

Dotadas de fundamentações epistêmicas próprias, cada uma dessas abordagens preconiza regimes didáticos próprios, coerentes com os valores, conceitos, visões de mundo e posicionamentos político-ideológicas que erigem. Todavia, por mais que elas sejam minuciosamente elaboradas e bastante claras nas suas prescrições, cumpre salientar que, na esfera da intervenção pedagógica em si, torna-se deveras difícil os docentes atuarem seguindo à risca as diretrizes específicas que uma ou outra abordagem particular preconiza.

Isso porque, malgrado guardar certa autonomia em relação aos ditames do mundo externo, a escola não existe separada dos acontecimentos verificados no curso da vida social; logo, os eventos desencadeados no seu interior são prenhes de contradições e imprevistos não contemplados na maioria das literaturas especializadas (FERREIRA, 1995).

Em função disso, com razoável frequência, o professor da área de Educação Física se vê, na prática cotidiana, diante de desafios cuja urgência de resolução lhe forçam, de imediato, a efetuar arranjos de ações, não só combinando muitas das abordagens citadas (o que, de certo, não agradaria a muitos dos teóricos responsáveis por criá-las!), mas também adicionando a elas parte dos múltiplos saberes triviais que a experiência profissional lhe permitiu acumular.

Portanto, ao final de tudo, é lícito afirmar que acabam predominando não formas de atuação pedagógica universalmente bem definidas, mas conjuntos de bricolagens individuais nascidas de convicções subjetivas diante de dificuldades surgidas ao sabor do acaso, repletas de soluções pragmáticas, muitas vezes atinentes com o modo de agir do senso comum.

Mas, e do lado do discente, que efeitos essa situação é capaz de gerar? Grosso modo, o que há é uma multiplicidade de vivências educativas não necessariamente 
convergentes com as melhores oportunidades de crescimento e desenvolvimento motor, cognitivo e afetivo. Isso porque, conforme a argumentação exposta acima, se a diagramação dos ambientes de ensino deriva de escolhas conceituais orientadas pela subjetividade dos mestres, escolhas essas acrescidas de dados oriundos do acúmulo das vivências pessoais que eles tiveram, então os discentes tendem a ser um reflexo direto das suas capacidades e afetos pessoais (BATISTA, 1996).

De fato, caso o professor se mostre um bricoleur sensível, criativo e inovador, pode-se esperar dos seus artifícios o aparecimento de conjunturas didáticas ricas e proveitosas para os alunos, os quais serão os maiores beneficiados do seu agir. Mas, caso não o seja, fatalmente, o cenário oposto tenderá a prevalecer.

Ademais, estima-se que, da parte dos discentes mergulhados nas tessituras de tão multifacetados quadros, diferentes representações sobre as finalidades, conteúdos e importância cotidiana da Educação Física sejam edificadas (FARIA JÚNIOR, 1987). Por conseguinte, no rastro dessa colocação, podemos esperar que a configuração das atitudes que esses docentes exibem no que tange às suas compreensões sobre o papel da Educação Física na educação básica também mostre bastante variabilidade.

Vale lembrar que atitudes são disposições para comportamentos construídas em franca interação com o meio ambiente externo (SHIGUNOV, 1993). Logo, tentar examiná-las constitui algo estratégico caso se queira aferir os modos de pensar, agir e imaginar dos sujeitos.

No campo da Educação, estudos que focalizam as atitudes de estudantes são relevantes, porque permitem aferir como eles compreendem normas de convívio, papéis, conhecimentos e funções de ordenamento social (CAMPOS, 1986). Além disso, tais trabalhos igualmente servem para mapear até que ponto a execução dos planejamentos pedagógicos, nas suas dimensões micro e macroscópicas, coincidem com o alcance dos objetivos de ensino estabelecidos.

Destarte, o objetivo deste estudo consiste em caracterizar as atitudes de discentes do ensino médio do município de Parintins, Amazonas, face ao cotidiano das suas aulas de Educação Física escolar. A justificativa para a efetivação deste trabalho empírico parte da combinação de: (1) constatações históricas; e (2) questões atuais.

No que concerne ao item 1, em meados da década de 1970, durante o governo do General Emílio Garrastazu Médici, o Ministério da Educação e Cultura estabeleceu como uma de suas principais prioridades a promoção de atividades educacionais na Região Norte do país como forma estratégica de atenuar suas discrepâncias socioeconômicas em relação aos centros mais desenvolvidos do Sul e Sudeste.

Para tal, alunos e professores de universidades de São Paulo, Rio de Janeiro, Minas Gerais, Rio Grande do Sul etc., foram convidados a se cadastrar em um programa de integração nacional denominado "Projeto Rondon", direcionado à execução de trabalhos voluntários em comunidades ribeirinhas e cidades interioranas do Amazonas, Acre, Roraima, Rondônia, Pará e estados afins (TENÓRIO, 1974). Ao final de quatro meses, os alunos voluntários teriam essa participação convertida em créditos na disciplina "Estudos de Problemas Brasileiros" (EPB), a qual era obrigatória em todos os currículos das universidades públicas brasileiras.

Cabendo à Universidade do Estado do Rio de Janeiro a realização de atividades na região do Baixo Rio Amazonas, essa instituição optou por criar um campus avançado no município de Parintins, onde instituiu o subprojeto "Educação de Base" em parceria com o Programa "Tempo de Integrar", da Rádio Alvorada de Parintins (BRASIL, 1980). Dentre os objetivos do subprojeto "Educação de Base", a formação de professores de Educação Física através de cursos modulares despontou como uma prioridade básica, porquanto as autoridades militares consideravam as práticas esportivas um eficaz meio de desencadeamento, junto às populações infantil e adolescente, da identidade cívica. 
Na avaliação de Rodrigues e Pasquali (2007), a jovem população adulta da cidade de Parintins de então absorveu o supracitado ideário preconizado pelo Projeto Rondon, haja vista que por volta de trinta professores de Educação Física foram diplomados na época. Até hoje, alguns professores formados naquele momento ministram aulas de Educação Física em instituições de ensino da região do Baixo Amazonas.

Sobre o item (2), é sabido que, nos últimos dez anos, os governos federal e estadual têm colocado em prática uma política de expansão do ensino superior universitário público para áreas distantes das capitais dos estados, concentrada na criação de novos campi ou expansão de alguns já existentes em locais que até então nunca haviam sido contemplados.

Em 2006, a cidade de Parintins recebeu dois campi universitários permanentes, um da Universidade Federal do Amazonas e outro da Universidade Estadual do Amazonas, com o oferecimento de cursos de licenciatura em Educação Física em ambos. Assim, mais de trinta anos após a presença do Projeto Rondon, novos professores de Educação Física estão sendo formados nessas instituições, porém em uma perspectiva de intervenção pedagógica diferente da adotada por seus predecessores dos tempos de regime militar, pois está arraigada em prerrogativas curriculares diferenciadas e contemporâneas.

Desse modo, o desenho contextual da Educação Física escolar nas escolas da cidade de Parintins indica que, nos tempos presentes, novas maneiras pedagógicas de pensar, agir, planejar e avaliar vêm sendo interpostas à tradição vigente. Em termos de abordagens ou concepções pedagógicas, pode-se dizer que, nos espaços escolares municipais, desde os anos de 1970 até hoje, predomina a tecnicista que, pouco a pouco, vem perdendo espaço devido à chegada de algumas outras concepções calcadas em fundamentos epistemológicos diferentes e atuais, merecendo destaque a dos Parâmetros Curriculares Nacionais e a da pedagogia crítico-social dos conteúdos.

No mais, urge reiterar a virtual relevância social do estudo ora em apresentação, na medida em que contribui para disponibilizar aos docentes que atuam na Educação Física escolar um leque de informações sistematizadas acerca da natureza do ambiente em que militam. Em tese, isso Ihes permitirá refletir com mais profundidade sobre os processos de ensino-aprendizagem que conduzem.

\section{ATITUDES E DIMENSÕES DA AFETIVIDADE NA EDUCAÇAO FÍSICA ESCOLAR}

A atitude é uma prontidão mental que serve para os seres humanos verificarem a ordem e a consistência do que as pessoas dizem, pensam e imaginam. Desta forma, elas suscitam certos comportamentos favoráveis ou desfavoráveis em relação uma pessoa, objeto ou ideia, evidenciadas por manifestações sob a forma de palavras ou atos.

Lima (2004), afirma que as atitudes são importantes fatores na previsão do comportamento humano, mas distingue entre as atitudes gerais face a um objeto e as atitudes específicas face a um comportamento relacionado com um objeto de atitude. Nesse sentido, as tomadas de atitudes dos discentes podem ser expressas como respostas aos atos pedagógicos do professor.

Da mesma forma, Duck (1986) lembra que atitudes são modificáveis ao longo do tempo, na medida em que é possível ensiná-las e aprendê-las. Ou seja, é algo aprendido, tendo um fundo emocional, que leva o sujeito a pensar, sentir, perceber, e também agir de uma maneira consistente, com manifestações de comportamento favoráveis ou desfavoráveis em relação a uma pessoa, objeto ou ideia.

Além do mais, salienta Berkowitz (1980), é a partir da sociabilidade entre as pessoas que se dá o aprendizado das atitudes. Por esta razão, muitas vezes, atitudes idênticas perante um mesmo fenômeno se originam de diferentes percepções dele, assim como pode resultar em atitudes divergentes frente a esse mesmo fenômeno. Em 
resumo, as atitudes de alguém denotam a maneira como sua personalidade lida com os matizes do real.

Neste entendimento, as atitudes se constituem como motivações dos comportamentos não estão diretamente ligadas à personalidade, sendo muito suscetíveis às influências externas. Sendo assim, desempenham um papel secundário e superficial no contexto das emoções e motivações do ser humano.

Outro fator relevante, e que está inteiramente relacionada com as atitudes, referese a questão da afetividade. Nas observações de Tassoni, (2000), a afetividade e os fenômenos afetivos simulam a forma como os acontecimentos refletem na natureza sensível do ser humano, os quais lhe disseminam um arranjo de reações matizadas que definem sua forma de ser, existir e se relacionar no mundo.

Nesta direção, Almeida (2001) suscita que a afetividade acena a um domínio funcional, sendo, pois, seu desenvolvimento condicionado à ação de dois fatores: o orgânico e o social, entre os quais há uma relação intrínseca, de tal modo que as qualidades anódinas de um possam ser sobrepujadas pelas qualidades mais aderentes do outro.

As intervenções de afetividade são muito dependentes das considerações individuais do aluno, ou, como coloca Bloom (1981), são altamente influenciadas pela concepção que ele possui da sua própria competência na aprendizagem da matéria escolar. Por isso, é necessário entender que os comportamentos são divididos em duas categorias polares: afetividade positiva e negativa (CARREIRO DA COSTA, 1988).

Afetividade positiva: Considera-se como representativas da afetividade positiva as intervenções expressas pelo professor de: elogiar, usar o primeiro nome, expressar-se com manifestações de urbanidade. O professor como ser humano, no dizer de Fernandes (1990), deve ser preparado e ter maturidade para suportar a carga de agressividade ou afetividade desmedida, com conotações positivas ou negativas, revelando-se com conhecimento para compreender e, principalmente, funcionar como um suporte das transferências dos alunos, não se deixando abalar pelas constantes manifestações, mas assumindo-as como polo de referência para os educandos.

As atitudes das pessoas, em geral, são manifestações de estados emocionais. As atitudes e os comportamentos dos professores devem exercer uma ação marcante sobre a criança, na medida em que serão, em grande parte, responsáveis pela estruturação da personalidade e, desta forma, pela orientação para sua vida futura.

Afetividade negativa: Compreende os comportamentos manifestos pelo professor de: criticar, agredir e punir. Deve-se entender afetividade negativa como toda manifestação de alguém, verbal ou não, para criticar, ironizar, menosprezar, admoestar, ameaçar, agredir, castigar ou punir toda e qualquer atuação de outrem. Toda pessoa humana possui seu estereótipo com conotações do bom e mau, moral e imoral, bonito ou feio, representando a imagem que é o diagnóstico feito com base em semelhanças, com imagens ao sabor da avaliação global da pessoa, corrobora Shigunov (1993).

A atitude do professor varia de turma para turma, entre os indivíduos, sendo produtora, muitas vezes, de um tratamento desigual e diferenciado. Apesar de não ser totalmente consciente, esta atitude do professor produz nos alunos os seus efeitos, muitas vezes negativos e danosos, como alertam Santos (1991) e Valente (1990).

Por conseguinte, perante as diferenças e manifestações dos alunos, os professores são aconselhados a terem atitudes positivas como formas mais eficazes de motivação e condução de uma aula. Mas nem sempre é assim, e no desenrolar de uma aula, no caso específico de Educação Física, como afirma Piéron (1988), não há nada mais frustrante na função do professor do que ter de "lutar" constantemente para os alunos terem comportamentos que os levem a um trabalho agradável e consequente.

O trabalho escolar nunca terá atingido seus objetivos e nunca trará satisfação se o professor e os alunos estiverem em constante conflito. Contudo, este problema 
transcende o campo metodológico da aula e deve tratar-se de preocupação cotidiana de um professor, quando se considera que a aula deveria ser uma intervenção agradável entre pessoas.

Autores como Fernandes (1990) e Luck e Carneiro (1983), entendem que a escola tem obrigação de transmitir valores, atitudes, interesses, mesmo àqueles que são difíceis de ser postos em prática, tais como igualdade social para todas as pessoas, amor, amizade, preservação do meio ambiente.

Para Shigunov (1993), deve-se dar atenção ao desenvolvimento afetivo, tendo em conta o funcionamento total do ser humano em qualquer circunstância. O que resulta em parcelas de sentimentos e emoções. O controle e a compreensão, além da adequação e eficácia, neste domino, passam pela vertente do reconhecimento da importância e necessidade de implantação nas escolas.

Para que o papel de promoção do desenvolvimento integral do educando seja cumprido, a escola deve ajudá-lo a aprender em todos os sentidos, portanto não somente quanto ao conhecimento e habilidades intelectuais, mas também, quanto a habilidades sociais, e pessoais como atitudes, valores, ideais, interesses do seu mundo interior (SHIGUNOV, 1993).

Desse modo, a escola não pode omitir-se da responsabilidade na ampliação, consciente e intencional, de atitudes positivas necessárias para o desenvolvimento do educando, no sentido social e pessoal (FERNANDES, 1990).

Corrobora Shigunov (1993), que o comportamento humano é classificado em três aspectos: pensamentos, sentimentos e ação. Estas conotações, assumem sentidos mais amplos e fazem entender-se como parte constituinte dos domínios cognitivo, afetivo e psicomotor.

Assim, tanto os aspectos cognitivos como afetivos e também psicomotores funcionam interligados na determinação do comportamento humano, uma vez que a pessoa responde às mais diferentes situações que a vida lhe apresenta como um todo (LUCK; CARNEIRO, 1983).

Embora os aspectos cognitivos, afetivos e psicomotores sejam examinados separadamente uns dos outros, para melhor entendimento e atuação mais eficaz o processo educativo deve buscar harmonizar as três dimensões, (os três domínios), não só com vistas à promoção do desenvolvimento do educando a longo prazo, mas também com vistas à aprendizagem de efeito imediato, afirmam Luck e Carneiro (1983).

Como foi frisado por Merrett e Wheldall (1990), as atitudes e comportamentos do professor possuem um papel preponderante para uma substancial melhoria comportamental dos alunos, pelas modificações operadas em alguns dos muitos componentes da aprendizagem. Para Merrett e Wheldall (1990), só pode haver um ensino positivo se as demonstrações de comportamentos e atitudes positivas dos professores forem observáveis para os alunos, devendo isto consistir numa atuação trinada e consistentemente assumida.

A trilogia escola-professor-aluno é interdependente, e a interação positiva também passa pela cordialidade de comunicação que deve haver entre as pessoas, como diz Gibb (1980). O professor nunca deve esquecer que todo aluno é possuidor de uma personalidade e esta não é largada à porta da escola, mas é com ela que o aluno vai interagir com relação ao professor, ao método, à aula à escola, como evidencia Shigunov (1993).

Sprinthall e Sprinthall (1987), sugerem que os professores devem ter atitudes que proporcionem, entre outros, os seguintes elementos para os alunos: tempo de prática, uso do reforço e feedback.

Segundo SCHMIDT (1993), o reforço tende a fazer com que o aluno repita ou não determinada ação. Com o reforço positivo o aluno tenderá a repetir aquela ação, pois o 
fator motivacional oferecido pelo professor incentivará nova tentativa da mesma ação. Em contrapartida, o reforço negativo inibe qualquer tentativa futura, que o aluno possa vir a fazer. Esse tipo de reforço deve ser utilizado com muita cautela devido ao fator desmotivacional.

Magill (2000) sugere que a qualidade da informação e a qualidade de prática são fatores determinantes para atingir os estágios mais avançados da aprendizagem. Dentre esses fatores, uma das mais importantes estratégias instrucionais estudadas pela aprendizagem das habilidades motora é o feedback. O feedback aumentado está relacionado às informações fornecidas por fontes externas (professor, técnico, vídeo, dentre outros), as quais têm como função ampliar ou suplantar o feedback intrínseco (órgãos sensoriais).

No entendimento de MOTA (1989), o feedback só é considerado como tal quando o aluno o entende como um reforço. Ao passar o feedback o professor deve observar fatores como a faixa etária, a experiência motora e a natureza do erro de execução.

De acordo com Magill (2000), um instrutor pode usar o feedback aumentado para modificar a percepção que a pessoa tem de sua própria capacidade de executar uma habilidade. Essa é uma forma eficiente de motivar a pessoa a continuar a perseguir a meta de uma tarefa ou desempenho de uma habilidade.

As evidências experimentais têm mostrado consistentemente que os professores de Educação Física fornecem vários tipos de feedback aumentado e apresentam essa instituição com graus de frequência variáveis para seus alunos em aula (MAGILL, 2000).

Por exemplo, Solomon e Boone (1993, apud MAGILL, 2000) mostram que, numa aula de Educação Física, os alunos com alta capacidade de percepção demonstraram maior persistência no desempenho de habilidades e apresentaram expectativas de desempenho mais altos que aqueles com baixa capacidade de percepção.

Em sua pesquisa sobre auto eficácia relacionada ao desempenho de habilidades, Feltz (1992) conclui que o sucesso ou fracasso do desempenho passado é um mediador chave da percepção que a pessoa tem de sua própria capacidade. Uma implicação lógica desses resultados é que um instrutor ou terapeuta pode apresentar o feedback aumentado de modo influenciar a forma como pessoa encara seu sucesso ou fracasso. Por isso o feedback aumentado pode influenciar na decisão da pessoa em persistir no desempenho de uma habilidade.

A partir disso, fica notório que os comportamentos do domínio afetivo devem ser considerados como importantes para o processo educativo, uma vez que estão presentes e atuantes em todos os momentos e circunstâncias. A sua influência se faz, também, nos aspectos da qualidade, motivação, tendências e inspiração das diferentes maneiras de atuação, tanto do professor como do aluno.

A promoção e desenvolvimento de comportamentos no domínio afetivo, devem ser vistos, segundo Fernandes (1990), como um esforço central e sistemático da ação educativa. A consecução dos comportamentos do domínio afetivo, ao qual está vinculado o desenvolvimento integral pretendido, também deve vincular-se uma política educacional, à sensibilização e habilidades dos professores.

Concomitante, o grande desafio da escola e, principalmente, do professor é determinar o que os alunos devem aprender, o que podem e o que não podem fazer e aquilo que se pretende com o trabalho escolar. Dessa forma, o professor deve definir as expectativas e traçar os limites perante a turma, e o mais importante é conseguir que eles sejam aceitos.

\section{PLANEJAMENTO EM EDUCAÇÃO FÍSICA ESCOLAR}

$\mathrm{Na}$ escola, o professor deve orientar suas aulas em um plano de ensino que the é apresentado, como sugere Dieckert (1997). O plano de ensino, embora limite as 
possibilidades de decisão do professor, serve-lhe como auxiliar de planejamento. 0 treinador ou técnico desenvolve para os seus atletas um plano de treinamento para os objetivos a serem alcançados a curto, médio e longo prazos, com os conteúdos necessários e cargas e dosagens de trabalho adequadas, levando em consideração suas experiências e seus conhecimentos científicos em relação aos mais altos rendimentos esportivos desejados no momento.

Ainda segundo Dieckert (1997), o planejamento se refere ao estabelecimento de metas para o alcance de um objetivo, que assegura maior probabilidade de êxito. $O$ estabelecimento do objetivo no esporte de alto nível é claro: o rendimento máximo, o melhor rendimento pessoal, o recorde, o campeonato. A orientação de objetivo no esporte de massa ou de tempo livre depende dos objetivos do grupo e das capacidades e expectativas dos participantes.

Para o planejamento de aulas de esporte (planejamento didático) - considerando aqui o esporte como conteúdo programático fundamental desta disciplina -, os professores de Educação Física deverão ter consciência dos objetivos que devem ser alcançados com o esporte e o movimento. Os objetivos e o planejamento não devem ser determinados ou executados sem levar em conta as condições prévias que o professor e seus parceiros (alunos) trazem para a referida aula:

a) condições dos participantes no grupo - grupo etário; sexo; pré-requisitos físicos; graus de desenvolvimento físico e psicossocial; comportamento diante de situações de conflito; comportamento frente a situações de risco, medo, coragem; estado de saúde; perturbações; aptidão motora; capacidades intelectuais; conhecimento da matéria; motivação, interesse no esporte; grau de expectativa; status social.

b) condições socioculturais, políticas e organizacionais - expectativas da sociedade em relação ao papel do grupo e de cada um; posição e função do esporte e da Educação Física do ponto de vista da sociedade como um todo; relação do clube esportivo e da escola com os demais campos sociais, no plano local e regional (por exemplo, em relação à família, à escola, aos empregados, à Igreja, ao comércio, aos partidos, à imprensa, ao rádio e à televisão); expectativa da sociedade, dos pais, da escola, dos dirigentes de clubes (por exemplo, a expectativa em relação ao sucesso); tamanho e estrutura do clube; condições de espaço, material e pessoal (instalações esportivas, equipamentos, pessoal docente e administrativo); tamanho e estrutura do grupo de esporte; participação irregular; formação inconstante do grupo (flutuação), possível heterogeneidade do grupo em relação às diferenças de idade, sexo, estatura, rendimento e interesses; condições climáticas (programas alternativos); instalações ao ar livre/ em ginásios.

Paralelamente às condições supracitadas, também são importantes para 0 planejamento as situações de vida presentes e desejáveis: tempo livre como situação de vida e que sempre se redefine e se redimensiona com o avanço da idade, com os crescentes acontecimentos de doença, maior ou menor capacidade de esforço, mudança de status social etc.; reflexos nas condições de trabalho (p. ex.: deficiência de movimento, sedentarismo, monotonia, sobrecarga psíquica, desemprego); vida familiar, ciclo de amigos, casais com ou sem crianças pequenas, crianças em idade escolar e adolescentes, papel dos avós, ser sozinho; região de moradia, valor do tempo livre nas dependências da residência, natureza circundante; férias, excursões de fins de semana.

Todos esses fatores são condições fundamentais para o processo de ensinoaprendizagem. A aprendizagem é um processo contínuo que ocorre durante toda a vida dos indivíduos, a qual, segundo Piaget (1993, p. 113), "é uma modificação duradoura do comportamento, em função de aquisições devidas a experiências". Tal fator constitui um ponto focal do processo de ensino. 
Dessa forma, as ações de ensino e os procedimentos didáticos têm que estar estruturados de forma coerente em relação ao propósito que perseguem. Isso induz a pensar que esses procedimentos didáticos precisam estar de acordo com o planejamento sistemático e ser produto de improvisação ou de inspiração pessoal no momento das atividades. $\mathrm{O}$ aprendizado ocorre com determinação e vontade de aprender. O aluno é ponto chave desse processo. Ele é a causa desencadeadora de uma linha educacional progressiva e autônoma. A escola e o professor são efeitos de ação contínua e sistemática: existem em função do aluno.

Carreiro da Costa (1988) salienta que os níveis de aprendizagem estão ligados ao tempo que o aluno está engajado nas atividades de aprendizagem, sendo, assim, ligado à capacidade do professor de organizar e gerir eficientemente a classe para proporciona-lhe o máximo de tempo para a aprendizagem.

O planejamento do ensino em uma perspectiva crítica de Educação, que pressupõe a relação aluno x professor $x$ escola, consiste em atuar com responsabilidade, precisão e coerência. Sabe-se, porém, que toda mudança requer um planejamento, um estudo minucioso de causas e efeitos, um plano executável e direcionado.

Desse modo, o planejamento escolar deve ser direcionado e coerente com as mudanças iminentes. Freire e Shor (1987) sabiamente enunciam que o espaço pedagógico é um texto para ser constantemente "lido", "interpretado", "escrito" e "reescrito". Nesse sentido, os autores enfatizam que, se os professores ou os alunos exercessem o poder de produzir novos conhecimentos em classe, a partir dos conteúdos fixados pelos currículos escolares, estariam de fato reafirmando seu poder de transformação da sociedade (FREIRE; SHOR, 1987).

Para realizar a ação docente de facilitação do aprendizado, o professor deverá operar com elementos que, basicamente, são: os conteúdos de ensino, os planejamentos didáticos e os meios materiais. Dessa forma, todo professor, para desenvolver seu trabalho docente de maneira satisfatória, em primeiro lugar, deve possuir conhecimento suficiente dos conceitos da matéria a ensinar. Em segundo lugar, deve ter uma formação específica, sendo assim, detentor de conhecimentos e recursos didáticos que lhes permitam construir uma metodologia adequada ao seu contexto de ensino. Em terceiro lugar, o professor deve dispor, no mínimo, de meios materiais que possam dar suporte às suas aulas.

Diante das situações, floresce a didática do planejamento que acontece no dinamismo, no incentivo, na arte, na técnica, na investigação e na capacidade de avaliação do docente, em uma visão ampla e inovadora, evidenciando, pois, que alunos e professor são os elementos centrais no processo de ensino-aprendizagem.

\section{PROCEDIMENTOS METODOLÓGICOS}

O desenvolvimento do estudo, delineado como descritivo e de natureza exploratória, a partir de uma abordagem quantitativa e qualitativa, obedeceu a procedimentos éticos, metodológicos e estatísticos. Em um primeiro momento, procedeu-se a sua submissão, ainda enquanto projeto de pesquisa, ao Comitê de Pesquisa do Instituto de Ciências Sociais, Educação e Zootecnia da Universidade Federal do Amazonas, com aprovação chancelada em 22 de março de 2012.

Para os pesquisadores terem acesso às dependências das escolas, solicitou-se uma autorização formal à Coordenadoria Regional de Educação de Parintins - CREP/ SEDUC, concedida após reunião com os gestores escolares, quando foram explicitados a natureza, os objetivos e a metodologia do estudo. Os contatos propriamente ditos aconteceram no interior de cada escola, após as aulas de Educação Física, nos quais os alunos receberam explicações sobre os motivos do trabalho, a confidencialidade das informações fornecidas e a não necessidade de identificação pessoal. Os discentes aceitaram de forma voluntária participar desta pesquisa, procedendo, em seguida, à assinatura do Termo de Consentimento Livre e Esclarecido - TCLE. 
Sobre o grupo-alvo, ele consistiu de 40 (quarenta) discentes, sendo 20 (vinte) mulheres e 20 (vinte) homens, todos com idades oscilando entre 15 (quinze) e 19 (dezenove) anos, regularmente matriculados em 4 (quatro) instituições de ensino da rede estadual localizadas no município de Parintins $/ \mathrm{AM}^{1}$, quais sejam: Tomaszinho Meirelles (1), Senador João Bosco Ramos de Lima (2), Colégio Batista de Parintins (3) e Dom Gino Malvestio (4).

Para este estudo, utilizam-se técnicas e instrumentos, cuidadosamente definidos, para a coleta de dados. De acordo com Severino (2007, p. 124), "as técnicas são os procedimentos operacionais que servem de mediação prática para a realização das pesquisas". Para isso, fez-se uso da observação sistemática, da aplicação de questionário sóciodemográfico e da "Escala Adams" para medição de atitudes discentes em relação ao professor de Educação Física.

A observação sistemática foi importante para obter um panorama acerca das atitudes e comportamentos dos discentes frente às aulas de Educação Física e ocorreu em todo o processo de realização da pesquisa. Lakatos e Marconi (2007, p. 195) afirmam que a observação sistemática é realizada em condições controladas que visam responder a propósitos pré-estabelecidos, ou seja, "[...] o observador sabe o que procura e o que carece de importância em determinada situação; deve ser objetivo, reconhecer possíveis erros e eliminar sua influência sobre o que vê ou recolhe". Essa técnica foi fundamental para aferir as diferentes atitudes dos discentes, segundo sexo, idade e escolas, durante a realização das aulas de Educação Física, tanto teóricas como práticas.

O questionário sóciodemográfico foi aplicado aos discentes, de forma individual, nos dias de aulas de Educação Física, no período compreendido entre abril e maio de 2012. Os alunos foram informados sobre os objetivos da pesquisa, ação que precedeu o preenchimento dos questionários pelos sujeitos. Este instrumento, construído com base nas variáveis relacionadas a sexo, idade e instituição de ensino dos sujeitos pesquisados, adequou-se aos objetivos do estudo e compôs-se de questões fechadas.

A Escala Adams foi utilizada para mensurar as atitudes discentes em relação ao professor de Educação Física. Trata-se de um questionário contendo um conjunto de quarenta afirmações bidirecionais do tipo "concorda" ou "discorda", cujos conteúdos referem-se a situações hipotéticas normalmente verificadas no âmbito da Educação Física escolar. O índice de confiabilidade do teste, segundo Mathews (1980), é de 0,84.

No que concerne à marcação dos escores do teste, diferentes graus são atribuídos apenas aos itens "concorda", sendo desprezados os "discorda". Os graus não são os mesmos para cada afirmação concordante, variando de uma para a outra. O resultado é a soma do valor de todos os escores concordantes dividida pelo número de itens assinalados. De modo geral, escores nominais elevados indicam predisposições a atitudes consideradas positivas no que tange ao objeto pesquisado, neste caso, às aulas de Educação Física escolar.

Depois de aplicados os questionários, os dados brutos foram analisados segundo os procedimentos de estatística descritiva simples. De início, acharam-se os valores de média aritmética $(\overline{\mathrm{X}})$ com seus respectivos desvios-padrão, que correspondem aos escores nominais individuais. Em seguida, realizou-se a verificação da normalidade dos escores. Confirmados os índices de normalidade, procederam-se às análises estatísticas por variável controlada (sexo, grupos de idades e escola).

Os dados obtidos foram agrupados, tabulados e sistematizados a partir da utilização de planilha do programa Excel, com o auxílio do aplicativo Minitab. Dessa forma, os dados foram cruzados e obteve-se a porcentagem correspondente a cada categoria investigada.

\footnotetext{
Município localizado no estado do Amazonas, à margem direita do Rio Amazonas. É um dos 7 (sete) municípios que compõem a Região do Baixo Amazonas. Possui uma população estimada em 102.033 habitantes, segundo os dados do último Censo Demográfico do Instituto Brasileiro de Geografia e Estatística - IBGE (2010).
} 
Para a análise por sexo, recorreu-se ao teste "T-Student" - ou simplesmente teste "t" -, o qual permitiu inferir as diferenças estatisticamente significativas entre os grupos (masculino e feminino). Trata-se de um instrumento que permite comparar as médias de dois grupos independentes, ou seja, verificar se as médias entre esses grupos são significativamente diferentes.

Para as análises por idades e por escola, empregou-se a Análise de Variância (ANOVA) com entrada simples. A ANOVA, segundo Maroco (2003), é um teste paramétrico que pode ser utilizado para avaliar diferenças entre diversas situações, assim como para duas ou mais variáveis. Em relação aos níveis de significância, foram considerados, com base em Cowles e Daves (2004), os seguintes resultados: 1) significativo: probabilidade de erro inferior a $0.05(p<0.05) ; 2)$ muito significativo: probabilidade de erro inferior a $0.01(p<0.01)$; e 3 ) altamente significativo: probalidade de erro inferior a $0.001(p<0.001)$.

A hipótese inicial de trabalho foi a da não existência de diferenças significativas $(p<0.05)$ nas médias dos escores tanto para sexo como para grupos de idades e escolas. Vale lembrar que, para esses cálculos, usou-se o software SPSS. Por fim, essas informações foram representadas em tabelas para melhor visualização dos resultados.

\section{OS DADOS DA REALIDADE: análise e discussão}

Importa ressaltar que os resultados desta pesquisa correspondem a uma aproximação com a realidade e não implicam uma generalização dos fatores estudados nos demais ambientes escolares, dada a dinamicidade histórica do contexto social. Os dados foram analisados à luz da literatura referenciada neste estudo, tendo em vista a articulação entre teoria e prática, fundamental na pesquisa científica.

Na Tabela 1, tem-se os resultados da estatística descritiva por sexo e as informações do teste "t".

Tabela 1 - Resultado da estatística descritiva por sexo e resultados do teste " $\mathrm{t}$ "

\begin{tabular}{ccccccc}
\hline CATEGORIA & FREQUÊNCIA & MÉDIA & DESVIO PADRÃO & GI & T & $p$ \\
\hline M & 20 & 7,24920 & 0,504667 & 38 & $-0,651$ & 0,519 \\
\hline F & 20 & 7,34495 & 0,422459 & 38 & $-0,651$ & 0,519 \\
\hline
\end{tabular}

Fonte: Elaborada pelos autores (2013).

Em termos nominais, as mulheres apresentam uma tendência ligeiramente superior aos homens para atitudes consideradas afirmativas, positivas ou proativas em relação às aulas de Educação Física. Entretanto, observou-se que não foram acusadas diferenças significativas para os valores das médias da variável sexo. Ou seja, comparativamente, a natureza das atitudes de homens e mulheres é praticamente a mesma.

Luke e Sinclair (1991) obtiveram resultado semelhante em pesquisa efetuada na província da Colúmbia Britânica, Canadá, com 448 estudantes do décimo e do último ano escolar. No entanto, os autores também buscaram mapear que tipos de parâmetros pesavam mais na construção das atitudes tanto dos discentes masculinos como femininos, concluindo que os conteúdos curriculares, o comportamento docente, o ambiente de ensino, a autoimagem corporal e as facilitações pedagógicas constituíam os quesitos preponderantes.

Curiosamente, apenas como nota, vale sublinhar que a valorização da autoimagem corporal parece receber elevado grau de importância não só entre discentes do ensino básico, mas também entre os estudantes do último ano de cursos de graduação em Educação Física no Brasil, Estados Unidos e Europa, conforme mostram Costa e Cardozo (2009). Em uma investigação do tipo meta-análise, as autoras concluíram que se mostrar belo, musculoso e com boa postura figura como preocupação central desses futuros professores. Para eles, tão significativa para o sucesso profissional quanto o domínio de conhecimentos teóricos e práticos é a manutenção de uma aparência jovial, porque denota amor próprio. 
Particularmente, o resultado do trabalho de Luke e Sinclair (1991) se alinha com o diagnóstico feito por Eagly e Steffen (1986), proferido ainda nos anos oitenta em uma longa e exaustiva pesquisa de revisão sobre gênero e Educação Física escolar. Eagly e Steffen (1986) concluíram que diferenças estatísticas consideráveis entre atletas masculinos e femininos praticamente inexistiam quando se tratava de mensurar as atitudes de ambos durante jogos e competições esportivas realizados em aulas de Educação Física.

Finley \& Finley (2007) também visualizaram a mesma tendência em recente estudo sobre a natureza dos discursos midiáticos relativos a eventos de futebol escolar realizados em escolas na América do Norte. Ao contrário do que supõe boa parte do senso comum, dizem estes autores, mulheres e homens pouco diferem quanto ao teor de suas atitudes no transcorrer de jogos e atividades esportivas.

Além disso, o estudo de Krouscas Junior (1999) com 348 escolares de ambos os sexos no estado da Virgínia, Estados Unidos, detectou uma disposição mais intensa das mulheres na faixa dos dezesseis anos para atitudes negativas (falta de interesse, não cumprimento de tarefas e invenção de mentiras para faltar às aulas) face à Educação Física escolar.

Ademais, Omar-Fauze et al. (2009) observaram semelhante viés comportamental entre alunas do décimo ano da educação básica em Kuala Lumpur, capital da Malásia. Com efeito, assim como na pesquisa de Luke e Sinclair (1991), Krouscas Junior (1999) aferiu que os conteúdos curriculares, a atuação docente, o ambiente de ensino e a autoimagem corporal dos alunos eram os fatores comportamentais mais significantes.

Todavia, na contramão desses achados, encontra-se o trabalho de Figueiredo (1996), o qual, efetivado em escolas do Rio de Janeiro, evidenciou justamente uma maior predisposição positiva das alunas do ensino médio para participarem das atividades desenvolvidas nas aulas de Educação Física.

Em resumo, as produções acadêmicas elencadas, ainda que em número reduzido, permitem diagnosticar que a conjuntura em voga indica a não existência de algum viés comportamental dominante no que diz respeito às atitudes tanto masculinas quanto femininas. Em grande medida, a maior positividade, negatividade ou equanimidade das atitudes desses segmentos reside muito mais na conformação contextual dos ambientes de ensino-aprendizagem do que em singularidades de gênero.

Aprofundando a questão, Bañuelos (1996) assevera que a linguagem didática, o feedback, o uso do tempo e a delegação de tarefas à turma são os quesitos cujo bom equacionamento otimiza o aproveitamento da aula, o que necessariamente leva à consecução de atitudes positivas.

Ao observarmos os fatores relacionadas à faixa etária, podemos visualizar na Tabela 2 os seguintes resultados:

Tabela 2 - Resultado da estatística descritiva por faixa etária e resultados de análise de variância

\begin{tabular}{ccccccc}
\hline CATEGORIA & FREQUENNCIA & MÉDIA & DESVIO PADRÃO & GL & F & 3 \\
\hline 15 & 10 & 7,30487 & 0,441626 & 0,416 & 0,742 \\
\hline 16 & 12 & 7,34100 & 0,321554 & 3 & 0,416 & 0,742 \\
\hline 17 & 10 & 7,13475 & 0,762210 & 3 & 0,416 & 0,742 \\
\hline $18-19$ & 8 & 7,80476 & 0,413010 & 3 & 0,416 & 0,742 \\
\hline
\end{tabular}

Fonte: Elaborada pelos autores (2013).

Em termos de médias nominais, o grupo etário de 15 anos apresenta o menor valor de todas elas, enquanto que, no outro extremo, o de 18-19 anos, o maior. Ou seja, nominalmente, os alunos situados neste último grupo demonstram possuir disposição para atitudes com teores de positividade superiores aos dos outros colegas localizados nos grupos de idades mais jovens. Em compensação, os discentes na faixa dos 15 anos são os que têm os índices numéricos mais baixos no que tange às atitudes. 
Embora esses sejam apenas escores nominais, e isso deve ser frisado, vale ressaltar que eles abrem margem para reflexões sobre a influência do amadurecimento no processo de construção das atitudes. As revisões conceituais sobre currículo em Educação Física feitas por Cassidy (1994) sugerem a possibilidade de haver uma relação positiva entre ambas, quando os avanços na idade durante a fase de adolescência vêm acompanhados de alargamentos das oportunidades de experiência.

Nos casos em que isso acontece, a percepção subjetiva do mundo incorre em mudanças qualitativas, de modo que o entendimento sobre os papéis desempenhados pela família, religião, cultura e sociedade se torna menos pueril. Assim, uma vez que a escola e os conteúdos curriculares são elementos indissociáveis desse contexto, a compreensão de sua importância no dia a dia também tende a ser interpretada com mais racionalidade.

Para Cassidy (1994), quando os valores passionais são contrabalançados pela ascensão de outros com maior participação da cognição, estima-se que a personalidade, ao se achar diante da obrigação de tomar alguma atitude, não deixa de lado valores como otimismo, tolerância e paciência.

Esse ponto de vista encontra eco em Johnson (2000), para quem a natureza das vivências pedagógicas dos alunos, em espaços dentro e fora dos universos estudantis, reflete diretamente na qualidade das avaliações cotidianas que eles tecem dos conteúdos curriculares aos quais são submetidos. Segundo esse autor, discentes em fase escolar que, com o fluir dos anos, são expostos a situações existenciais diferenciadas e profícuas, fatalmente conseguem traduzir a riqueza dos aprendizados colhidos nesses ambientes em comportamentos ponderados e críticos.

Em termos de Educação Física escolar, as análises de Johnson (2000) apontam que estudantes submetidos a diversificadas situações socioculturais durante os primeiros vinte anos de vida, em geral, ajuízam com grande riqueza de detalhes os programas de ensino dessa disciplina à medida que saem da adolescência e iniciam a fase adulta, independentemente dos seus focos terem sido treinamento desportivo; recreação e lazer; ou promoção da saúde.

Para grupos de idades, após a aplicação do teste de Análise de Variância, também se percebe que não houve diferença estatisticamente significativa. Na perspectiva de Telama (1988), a verificação de cenários nos quais essa característica é patente, no fundo, retrata a vigência de certa homogeneidade nas percepções quanto aos conteúdos curriculares de ensino e respectivas oportunidades de desenvolvimento interpessoal que eles endereçam. A questão maior consiste em tentar desvelar quais ingredientes, e com que proporções, estão a determinar a emergência desse suposto consenso.

Em relação aos resultados por escola, vejamos a Tabela 3.

Tabela 3 - Estatística descritiva por escola e resultados do teste " $t$ " e resultados de Análise de Variância

\begin{tabular}{ccccccc}
\hline CATEGORIA & FREQUÊNCIA & MÉDIA & DESVIO PADRÃO & GL & $F$ & $P$ \\
\hline E.E. Tomazinho Meirelles (1) & 10 & 7,34070 & 0,271891 & 3 & 0,404 & 0,751 \\
\hline $\begin{array}{c}\text { E.E. Senador João Bosco Ramos } \\
\text { de Lima (2) }\end{array}$ & 10 & 7,40470 & 0,323497 & 3 & 0,404 & 0,751 \\
\hline E.E. Batista de Parintins (3) & 10 & 7,25440 & 0,367893 & 3 & 0,404 & 0,751 \\
\hline E.E. Dom Gino Malvestio (4) & 10 & 7,18850 & 0,761977 & 3 & 0,404 & 0,751 \\
\hline
\end{tabular}

Fonte: Elaborada pelos autores (2013).

Com efeito, em se tratando de médias nominais, as atitudes dos alunos matriculados nas escolas Colégio Batista de Parintins (3) e Dom Gino Malvestio (4) apresentam escores ligeiramente inferiores aos das escolas Tomaszinho Meirelles (1) e Senador João Bosco Ramos de Lima (2). Muito embora todas as quatro estejam localizadas na área urbana do município de Parintins e estejam sob os auspícios da administração pública, vale ressaltar - muito mais a título de um exercício de especulação cujo fim não é outro senão causar inquietações e ensejar futuras pesquisas qualitativas - o singular contexto ideológico das instituições (3) e (4). 
As escolas Colégio Batista de Parintins e Dom Gino Malvestio, mesmo tuteladas, na atualidade pela Secretaria Estadual de Educação do Amazonas, não foram originadas por nenhum tipo de ação político-legal da administração pública. Na verdade, elas tiveram suas respectivas criações efetivadas por missionários protestantes e católicos ainda no início da segunda metade do século XX, época em que o interior da região amazônica ainda era muito menos assistido pela gerência dos órgãos estatais brasileiros do que agora. Nesse período histórico, coube a muitas lideranças religiosas promover o crescimento e desenvolvimento de povoados e pequenas cidades por meio de fomentos à abertura de rotas fluviais, estruturação de portos etc.

As escolas (3) e (4) datam desse momento singular. Até hoje, as marcas da tradição responsável por sua origem seguem gravadas na arquitetura dos prédios, nos acervos das bibliotecas e na memória coletiva de professores, alunos e diretores. Portanto, ainda que não seja explícito, o imaginário desses grupos contribui para manter avivada uma parte de tal passado nas suas falas, decisões, medidas e opiniões. Parafraseando Faria Júnior (1989), tem-se nesse contexto vetores de um currículo oculto, pois correspondem a veículos comunicadores de conhecimentos, valores, crenças e normas morais através de vias veladas.

Dentre as possíveis informações propagadas por essa dimensão curricular oculta, pode ser que a ideia, cara às pedagogias religiosas, de que o culto ao intelecto supera em importância os atributos corporais da existência esteja em processo de atualização nas representações e práticas dos docentes e discentes. Tal assertiva é crível, ao menos como suposição teórica, porque a verificação das atitudes negativas dos discentes dessas escolas em relação à Educação Física escolar quando postas lado a lado com as dos colegas das escolas Tomazinho Meirelles (1) e Senador João Bosco Ramos de Lima (2) permite sua formulação. Novamente, cabe frisar que se trata de um raciocínio provocador e especulativo, cujo objetivo é fomentar o desencadeamento de futuras investigações comprobatórias ou negadoras da hipótese anunciada.

Finalmente, a ausência de diferenças estatisticamente significativas para escolas, após a aplicação do teste Análise de Variância, foi de novo reiterada. Em grande medida, um resultado dessa natureza foi igualmente obtido em pesquisa realizada nos anos 1990 na cidade do Rio de Janeiro, através da qual Lovisolo e Soares (1995) concluíram que as atitudes de estudantes do ensino fundamental perante os currículos escolares de Educação Física corroboravam muito mais o prazer que essa disciplina Ihes proporcionava no espaço escolar, independente da localização na geografia urbana do município (periferia, favelas, áreas centrais, zona rural) do que a aquisição de informações sobre a relevância das práticas esportivas para a manutenção da saúde.

\section{CONSIDERAÇÕES FINAIS}

A título de recapitulação, o trabalho em voga objetivou caracterizar as atitudes de discentes do ensino médio de quatro escolas do município de Parintins, Amazonas, perante as aulas de Educação Física escolar. Segundo a literatura pertinente, atitudes espelham, com razoável fidedignidade, a forma com que as circunstâncias determinantes do ambiente de ensino são geridas. Em tom metafórico, isso quer dizer que os alunos ressoam aquilo que os processos de ensino-aprendizagem lhes endereçam.

Observou-se também que, malgrado pulularem no Brasil diversas propostas teóricometodológicas sobre objetivos, meios e fins da Educação Física escolar, ainda assim uma gama considerável de autores endossa a criatividade, experiência e sensibilidade do docente como fatores cruciais da organização didática. Assim, dependendo da forma como o professor articula as diversas variáveis capazes de interferir na dinâmica das aulas que ministra, tanto para torná-las mais ricas e proveitosas como menos suscetíveis de desestruturações, nada melhor do que projetar no comportamento do aluno a condição de "termômetro" da efetiva proficiência desse agir. 
No que diz respeito aos resultados deste estudo, eles comprovaram inexistirem diferenças significativas nas atitudes discentes do ensino médio no que concerne a sexo, faixa etária e escola, não obstante os escores das médias nominais serem ligeiramente menores para: 1) homens; 2) indivíduos situados no grupo etário de 15 anos; e 3) escolas fundadas por missionários religiosos. No outro extremo, ainda em termos de médias nominais, as mulheres, os indivíduos com idade entre 18 e 19 anos e as escolas eminentemente laicas acusaram os valores mais altos. Isso significa que os homens, os jovens na faixa dos 15 anos e os alunos de escolas originadas no passado por iniciativas religiosas exibiriam, nominalmente, atitudes um pouco mais negativas em relação à Educação Física escolar do que as mulheres, os jovens na faixa dos 18 e 19 anos e os alunos das escolas não fundadas por motivos religiosos.

Em função dessa constatação e, igualmente, contabilizando as observações de Krouscas Junior (1999) e Luke e Sinclair (1991) - para quem os conteúdos curriculares, a atuação docente, o ambiente de ensino e a autoimagem dos alunos exercem influência direta na constituição dos comportamentos discentes -, algumas conclusões parciais podem ser anunciadas.

A primeira delas envolve o cruzamento de fatores levantados empiricamente com as informações do parágrafo anterior e responde ao seguintes questionamentos: Em instituições de ensino com visível orientação religiosa, até que ponto tal tendência ideológica influi na organização dos conteúdos curriculares, na dinâmica do ambiente de ensino e na conduta do professor de Educação Física? Supondo que haja essa influência, a natureza das atitudes discentes é ou não uma extensão dela? Eis questões que demandam maiores investigações.

Outro item sequioso de análises mais aprofundadas concerne aos muitos conteúdos de ensino da Educação Física escolar (esportes, danças, lutas, jogos, brinquedos cantados, mímicas corporais etc.). Em grande medida, ao menos como divagação teórica, espera-se que as preferências dos discentes por alguns, em detrimento de outros, seja algo perfeitamente normal. Aceitando essa hipótese de trabalho, infere-se que atitudes mais ou menos positivas variam segundo o perfil dos conteúdos trabalhados. Estudar a dimensão dessa virtual correlação, conteúdo por conteúdo, contribuiria demasiado para a ampliação dos conhecimentos vinculados ao tema em arrolo.

Além disso, diretamente ligada a essa problemática, está a necessidade de aprimoramento dos instrumentos de medida das condutas atitudinais em Educação Física escolar. A grande maioria das escalas e questionários estatisticamente validados para a aferição dessa valência psicossocial, como a Escala Adams (empregada no presente estudo), Escala McCloy ou a Escala Blanchard, dentre outras, incide apenas sobre situações corriqueiras dos processos de ensino-aprendizagem, sem olvidar do demasiado grau de generalidade das suas perguntas/assertivas (MATHEWS, 1980; TRITSCHLER, 2003). Sugere-se que instrumentos, cujo foco sejam os conteúdos de ensino específicos da Educação Física, pudessem ser formalizados, salvaguardadas as devidas regras científicas de validação, a fim de que novos e mais precisos dados possam vir à baila.

Para finalizar, nunca é demais lembrar o diagnóstico de Faria Júnior (1987), segundo o qual, dentro do contexto macroscópico da produção epistemológica em Educação Física enquanto área do conhecimento, os trabalhos vinculados ao setor escolar ratificam a grande complexidade que lhe permeia e que provavelmente nunca terminará. Assim, tão ou mais significativas do que a proposição de construtos teóricos cientificamente fundamentados são as pesquisas empíricas descritivas, pois nada mais profícuo do que entender o dia a dia nas suas facetas microscópicas enquanto marco norteador de ações pedagógicas coerentes, consistentes e fidedignas. 


\section{REFERÊNCIAS}

ALMEIDA A. R. S. O que é afetividade? Reflexões para um conceito. 2001. Disponível em <http://www.anped.org.br/24/T2004446634094.doc>. Acesso em: 08 de setembro 2012.

BAÑUELOS, F. S. Bases para uma didáctica de la educación física y el deporte. Madrid: Gymnos Editorial, 1996.

BATISTA, L. A. O conhecimento aplicado: a efetiva utilização do conhecimento contido no campo da biomecânica, nos processos de ensino de habilidades motoras desportivas. 1996. Dissertação (Mestrado em Ciências do Desporto) - Universidade do Porto, Porto-Portugal, 1996.

BERKOWITZ, L. Psicologia social. Rio de Janeiro: Interamericana, 1980.

BLOOM, B. S. Característica Humana e Aprendizagem Escolar. Porto Alegre: Editora Globo, 1981.

BRASIL. Ministério da Educação e Cultura. Departamento de Documentação e Divulgação. Uma visão do campus avançado pelo Conselho de Reitores das Universidades Brasileiras e Fundação Projeto Rondon. Brasília, DF: MEC; DDD, 1980.

CAMPOS, D. Psicologia da aprendizagem. Petrópolis: Vozes, 1986.

CASSIDY, R. Curriculum development in physical education. New York: Harper \& Brothers, 1994.

COSTA, F. A. A. C. O Sucesso Pedagógico em Educação Física: Estudos das condições e factores de ensino-aprendizagem associados a um êxito numa unidade de ensino. Dissertação de doutoramento, não publicada. Universidade Técnica de Lisboa, ISEF, 1988.

COSTA, V. L.; CARDOZO, E. Alguns sentidos da profissionalização no imaginário social de futuros profissionais de licenciatura em educação física. In: COSTA, V. L.; COSTA, M. R. (Org.). Imaginário e profissionalização em educação física: textos e contextos. Rio de Janeiro: Shape, 2009.

DARIDO, S. C. Educação física na escola: questões e reflexões. Rio de Janeiro: Guanabara Koogan, 2003.

DIECKERT, J. (Org.). Ensinar e aprender na educação física. Tradução de M. S. Sonnhilde Else Von Der Heide. Rio de Janeiro: Ao Livro Técnico, 1997.

DUCK, S. Human relationships. Los Angeles: Sage Publications, 1986.

EAGLY, A.; STEFFEN, V. Gender and aggressive behavior: a meta-analytic review of the Social Psychological literature. Psychological Bulletin, v. 100, n. 3, p. 309-330, 1986.

FARIA JÚNIOR, A. G. de. O essencial em didática. Rio de Janeiro: Eduerj, 1989. . Prática de ensino em educação física. Rio de Janeiro: Guanabara Koogan, 1987.

FELTZ, D. L. Understanding Motivation in Sport: A Self-Efficacy Perspective. In: ROBERTS, G. C. Motivation in Sport and Exercise. Champaign: Human Kinetics, 1992, p. 93-106.

FERNANDES, E. Psicopedagogia e Psicanálise da Educação. Editora Estante, Aveiro (Portugal), 1990. 
FERREIRA, N. T. Jogos escolares: a responsabilidade social do professor de educação física. In: VOTRE, S. J.; COSTA, V. L. M. (Org.). Cultura, atividade corporal e esporte. Rio de Janeiro: Editoria Central da Universidade Gama Filho, 1995.

FIGUEIREDO, C. A. Relações de sedução entre professor e aluna: análise de um discurso. In: VOTRE, S. J. (Org.). A representação social da mulher na educação física e no esporte. Rio de Janeiro: Editora Gama Filho, 1996.

FREIRE, P.; SHOR, I. Medo e ousadia: o cotidiano do professor. Rio de Janeiro: Paz e Terra, 1987.

GIBB, J. R. Comunicação defensiva. In C. D. MORTENSEN (org.) Teoria da Comunicação. Textos básicos. São Paulo: Editora Mosaico, 1980.

IBGE. Instituto Brasileiro de Geografia e Estatística. Censo demográfico. 2010. Disponível em: $<$ http://cidades.ibge.gov.br/xtras/perfil.php?lang=\&codmun=130340\&search=amazonas|parintins> Acesso em: 18 de agosto de 2012.

JOHNSON, M. L. Functional administration in physical and health education. Boston: Houghton Mifflin, 2000.

KROUSCAS JUNIOR, J. A. Middle school students attitudes toward a physical education program. 1999. Tese (Doutorado em Filosofia) - Virginia Polytechnic Institute, State University, Blacksburg-Virginia, 1999.

LAKATOS, E. M.; MARCONI, M. de A. Fundamentos de metodologia científica. 6. ed. 5. reimpr. São Paulo: Atlas, 2007.

LIMA, M. Atitudes: Estrutura e Mudança. In: Vala, J. \& Monteiro, M. Psicologia Social.. 1ª́Ed. Fundação Calouste Gulbenkian: Serviço de Educação e Bolsas, 2004.

LOVISOLO, H. R.; SOARES, A. J. Educação e educação física em escolas do Rio de Janeiro. In: LOVISOLO, H. (Org.). Educação física: a arte da mediação. Rio de Janeiro: Sprint, 1995.

LUCK, H.; CARNEIRO, D. G. Desenvolvimento Afetivo na Escola: Promoção, Medida e Avaliação. Petrópolis: Editora Vozes, 1983.

LUKE, M. D.; SINCLAIR, G. D. Gender differences in adolescent's attitudes toward school physical education. Journal of Teaching in Physical Education, v. 11, n. 1, p. 31-46, 1991.

MAGILL, R. A. Aprendizagem Motora: conceitos e aplicações. Tradução Aracy Mendes da Costa; revisão técnica José Fernando Bitencourt Lomônaco - São Paulo: Edgard Blucher, 2000.

MAROCO, J. Análise estatística com utilização do SPSS. 2. ed. Lisboa: Edições Silabo, 2003.

MATHEWS, D. Medida e avaliação em educação física. Rio de Janeiro: Interamericana, 1980.

MERRETT, F.; WHELDAL, K. Positive Teaching in the Primary School. Londres: Paul Chapman Publishing, 1990.

MOTA, J. As funções do feedback pedagógico. Lisboa: Horizonte, 1989.

OMAR-FAUZEE, M. S. et al. College students perception on physical education classes during their high school days. European Journal of Social Sciences, v. 7, n. 4, p. 69-76, 2009.

PIAGET, J. O nascimento do raciocínio na criança. 5. ed. São Paulo: El Ateneo, 1993. 
PIÉRON, M. Didactica de las Actividades Físicas e Desportivas. Madri: Gymnos Editorial, 1988.

RODRIGUES, M. C.; PASQUALI, S. M. 40 anos: a concepção político-estratégica dos campi avançados. Revista do Clube Militar, v. 426, n. 22, p. 1-3, out. 2007.

SANTOS, M. E. V. M. Mudança Conceptual na Sala de Aula: Um Desafio Pedagógico. Lisboa: Livros Horizonte, 1991.

SEVERINO, A. J. Metodologia do trabalho científico. 23. ed. São Paulo: Cortez, 2007.

SCHMIDT, R. A. Aprendizagem e Performance Motora: dos princípios à prática. Tradução Flávia da Cunha Bastos; Olívia Cristina Ferreira Ribeiro. São Paulo: Movimento, 1993.

SHIGUNOV, V. Pedagogia da Educação Física: O desporto coletivo na escola - os componentes afetivos. São Paulo: IBRASA, 1993.

SPRINTHALL, NORMAN A. \& SPRINTHALL, RICHARD, C. Educational Psychology. Nova York: Random House, 1987.

TASSONI E. C. M. Afetividade e Aprendizagem: A relação professor aluno. Dissertação de Mestrado, 2000. Disponível em: <http://www.anped.org.br/23/textos/1019t.PDF>. Acesso em: 06 de setembro de 2012.

TELAMA, R. Sports in and out of school. In: MALINA, R. (Ed.). Young athletes: biological, psychological and educational perspectives. Champaign, IL: Human Kinetics Publishers, 1988.

TENÓRIO, O. Oásis no inferno verde: Parintins. Boletim UEG, v. 94, p. 135, fev. 1974.

TRITSCHLER, K. Medida e avaliação em educação física e esportes de Barrow \& McGee. Barueri, SP: Manole, 2003.

TUBINO, M. J. As teorias da educação física e do esporte. São Paulo: Manole, 2002.

VALENTE, B. Educador ou Professor? Lisboa: Livros Horizonte, 1990. 